\title{
ANÁLISE DE DOIS PROGRAMAS (UFPR E USP) DE FORMAÇÃO DE ESTUDANTES DE FRANCÊS COM OBJETIVOS UNIVERSITÁRIOS (FOU): CONCEPÇÕES, CONTEÚDOS E MODALIDADES
}

\author{
Análisis de dos programas (UFPR y USP) para la formación \\ de estudiantes de Francés con Objetivos Universitarios (FOU): \\ concepciones, contenidos y modalidades
}

\author{
Deise Cristina de Lima PICANÇO \\ Universidade Federal do Paraná \\ deisepicanco@gmail.com \\ https://orcid.org/0000-0002-2234-2090 \\ Paula Tatyane Cardozo STEMBERG \\ Programa de Pós-Graduação em Direito \\ Universidade Federal do Paraná \\ paulastemberg@gmail.com \\ https://orcid.org/0000-0003-1443-6545
}

RESUMO: A partir do contexto vivenciado entre os anos de 2009 e 2012 na Universidade Federal do Paraná (UFPR), objetiva-se neste artigo compreender de que formas os cursos de língua francesa ministrados no Projeto Formação em Línguas para Fins Acadêmicos (IFA) contemplavam as expectativas de outros cursos identificados como Francês com Objetivos Universitários (FOU). Inicialmente identificam-se duas grandes tendências nesse movimento, que orientam o ensino de línguas a partir das necessidades de interações socioverbais dos aprendizes, por meio do ensino de LE que privilegia determinadas habilidades comunicativas e/ou determinados contextos de interação. Em seguida, analisam-se os programas de duas propostas de curso, nessa modalidade, oferecidos em duas universidades brasileiras entre os anos de 2011 e 2012: Formação em Francês para fins acadêmicos, na UFPR, e Francês para Objetivo Universitário, na USP. Em Considerações finais, relata-se a importância de cursos voltados especificamente ao público universitário e a singularidade dos cursos de FOU no âmbito do IFA, que já era evidente naquele período. PALAVRAS-CHAVE: Idioma para Fins Acadêmicos; IFA; Francês como Língua Estrangeira; FLE; Francês com Objetivos Universitários; FOU.

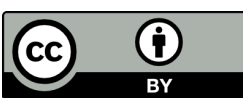




\begin{abstract}
RESUMEN: Se objetiva en este artículo compreender, según el contexto vivido entre los años 2009 y 2012 en la Universidad Federal de Paraná (UFPR), de qué formas los cursos de lengua francesa ministrados en el Proyecto Formación en Lenguas para Fines Académicos - IFA contemplaban las expectativas de otros cursos identificados como Francés con Objetivos Universitarios (FOU). Inicialmente se identifican dos grandes tendencias en ese movimiento, que orientan la enseñanza de lenguas a partir de las necesidades de interacciones socio-verbales de los aprendices por medio de la enseñanza de LE que privilegia determinadas habilidades comunicativas y/o determinados contextos de interacción. En seguida, se analizan los programas de dos propuestas de curso, en esa modalidad, ofrecidos en dos universidades brasileñas entre los años 2011 y 2012: Formación en Francés para fines académicos, en la UFPR, y Francés para Objetivos Universitarios, en la USP. En las Consideraciones finales, se relata la importancia de cursos direccionados específicamente al público universitario y la singularidad de los cursos de FOU en el ámbito del IFA, que era evidente en aquel período. PALABRAS CLAVE: Idioma para fines académicos; IFA; Francés como lengua extranjera; FLE; Francés con objetivos universitários; FOU.
\end{abstract}

\title{
INTRODUÇÃO
}

Cada enunciado do discurso constituído por um sujeito-autor tem o outro como elemento fundamental de existência devido ao seu aspecto dialógico. Ou seja, participa de uma cadeia de comunicação verbal, contando com participações ativas de inúmeros outros interlocutores. Essas participações se dão pela presença nos elos de comunicação anteriores nos quais ficaram marcadas opiniões, julgamentos, esclarecimentos, e na compreensão responsiva, pois "todo enunciado se elabora para ir ao encontro dessa resposta" (BAKHTIN, 1997, p. 318 e ss.). Ainda, nas palavras de Rocha, "as relações sociais, em todos os domínios, ocorrem entre sujeitos cultural e historicamente constituídos por meio da linguagem" (ROCHA, 2010, p. 23). Numa concepção sociocomunicativa $^{1}$ de linguagem como a bakhtiniana, que orienta nossas reflexões, as relações entre línguas e culturas, portanto, são constitutivas dos sujeitos, e também dos grupos sociais e dos contextos em que interagem. Para Volochinov (2017, p. 209), a

\footnotetext{
${ }^{1}$ Entendemos, assim como Bakhtin e o Círculo, que a natureza fundamental da linguagem é a interação socioverbal. Por isso partimos de uma perspectiva sociocomunicativa (ou sociointeracionista). Para essa perspectiva, a unidade de trabalho são os enunciados, entendidos como uma unidade de comunicação socioverbal, organizada a partir de gêneros do discurso, por isso essa perspectiva de linguagem também é conhecida como sociodiscursiva.
}

Revista X, v. 16, n. 4, p. 1160-1187, 2021. 
[...] consciência é uma ficção fora da objetivação, fora da encarnação em um material determinado (o material do gesto, da palavra interior, do grito). [...] Todavia, a consciência como expressão material organizada (no material ideológico da palavra, do signo, do desenho, das tintas, do som musical etc.) é um fato objetivo e uma enorme força social.

Segundo Kramsch (2017 p. 138-139), para Bakhtin, o diálogo, enquanto dever de responder o outro, composto por enunciados e respostas, é a via pela qual é construída a identidade cultural e pessoal, e mais do que isso, ele é capaz de conectar não somente os interlocutores, face a face, no presente, mas também passado e presente, leitores e autores de diferentes lugares que estejam distantes. É por isso que diferentes concepções de linguagem e sociedade geraram experiências diversas no estudo de línguas, que foram acompanhadas também por diferentes perspectivas de sujeito e aprendizagem (LEFFA, 1999; CELANI, 1997; PICANÇO, 2003; ROCHA, 2010). Até o início do século XX, as experiências hegemônicas estiveram focadas na forma da língua e na sua memorização ${ }^{2}$, tanto no Brasil como em quase todo o mundo ocidental. A partir da década de 1960, quando a Linguística Aplicada e as pesquisas sobre aquisição de linguagem começam a se fortalecer no Brasil, professores de línguas e pesquisadores passaram a reconhecer as necessidades dos aprendizes como um fator relevante no momento de planejar o ensino. Nessa mesma época, o termo ensino de línguas estrangeiras ${ }^{3}$ para fins especificos (ELE FE) começa a ser usado (CHAVES, 2006, p. 30; FERREIRA; ROSA, 2008; CELANI, 1997, p. 154), tanto no âmbito universitário quanto nas necessidades de conhecimento linguístico para o mercado de trabalho, com uma variedade de nomes e finalidades como inglês para negócios, francês para viagem, entre outros. Nas décadas seguintes, essa prática de ensino voltada para as necessidades específicas dos aprendizes ficou cada vez mais sofisticada conforme as pesquisas em Linguística Aplicada apontavam novos caminhos teórico-metodológicos, como as perspectivas cognitiva, comunicativa - em suas várias versões — e sociointeracionista (LEFFA, 1999, CELANI, 1997, ALMEIDA FILHO, 2015; TILIO, 2013).

\footnotetext{
${ }^{2}$ Os métodos mais conhecidos de ensino ficaram conhecidos como Gramática e Tradução, Método direto, Audio-lingual, Situacional ou Estruturo-Global (PICANÇO, 2003; CELANI, 1997).

${ }^{3}$ Embora acreditemos que o termo língua adicional seja mais adequado ao sentido e à pertinência do ensino de línguas, usaremos o termo língua estrangeira para dar certa fluidez ao texto na relação com a bibliografia específica, que segue usando essa nomenclatura.
} 
Ao participar das atividades do Projeto de Formação em Línguas para Fins Acadêmicos (IFA) ${ }^{4}$ nos anos de 2009 a $2012^{5}$, sentimos a necessidade de compreender de que forma os cursos de língua ministrados no Projeto contemplavam as expectativas de outros cursos identificados como Francês com Objetivos Universitários (FOU). Para isso, nossa reflexão identificou duas grandes tendências nesse movimento, que orientam o ensino de línguas a partir das necessidades sociointeracionais dos aprendizes: a primeira, por meio do ensino de LE que privilegia determinadas habilidades comunicativas; e a segunda, por meio do ensino de LE que privilegia determinados contextos de interação. Iniciamos nossa reflexão buscando compreender os contextos de oferta de cursos de Francês com Objetivos Universitários (FOU). Na sequência, analisamos duas propostas de curso, nessa modalidade, a partir de seus programas ${ }^{6}$, oferecidos em duas universidades brasileiras entre os anos de 2011 e 2012: Formação em Francês para fins acadêmicos, na UFPR (PICANÇO, 2012, 2019), e Francês para Objetivo Universitário, na USP (ALBUQUERQUE-COSTA, 2011). Por fim, trazemos algumas considerações, ainda que provisórias, sobre as reflexões realizadas acerca da importância de cursos voltados especificamente para o público universitário e a singularidade dos cursos de FOU no âmbito do IFA, que já era evidente naquele período.

\section{OS PRIMEIROS PASSOS DO ENSINO DE LÍNGUAS COM OBJETIVOS ES- PECÍFICOS E PARA FINS ESPECÍFICOS}

O Ensino de Língua Estrangeira para Fins Específicos (ELEFE) surgiu no início da década de 1960 no contexto acadêmico europeu e estadunidense e, conforme destacam muitos autores (CHAVES, 2006, p. 30; FERREIRA; ROSA, 2008; CELANI, 1997, p. 154), há certa dificuldade em se determinar se foi a Abordagem Comunicativa (AC) ou essa modalidade de ensino de línguas que surgiu primeiro. Esse detalhe, no entanto, só

\footnotetext{
${ }^{4}$ Como o projeto foi ficando cada vez mais conhecido, os alunos em geral passaram a chamálo de Idiomas para Fins Acadêmicos (IFA), já que o nome oficial (Formação em Línguas para Fins Acadêmicos) parecia muito longo. Esse nome fantasia - IFA — passou a fazer parte da identidade do projeto.

${ }^{5}$ Deise Cristina de Lima Picanço é idealizadora, junto ao professor Henrique E. Janzen, do Projeto Formação em Línguas para Fins Acadêmicos (IFA), sendo sua coordenadora entre 2015 e 2018 , e professora de Metodologia e Prática de Docência da UFPR; Paula Tatyane Cardozo Stemberg, foi aluna do curso de licenciatura em Letras, e bolsista de francês no IFA nos anos de 2010, 2011 e 2012.

${ }^{6}$ Nossa intenção neste artigo foi analisar apenas os programas dos dois cursos e não sua realização, considerando que aconteceram em 2012, na mesma época em que se intensificaram os programas de intercâmbio acadêmico estudantil, como o Ciências Sem Fronteiras.
} 
faz sentido se entendemos que as diversas nomenclaturas criadas para diferenciar as variações nas propostas de ensino de línguas para fins específicos têm uma história e aspectos teórico-metodológicos em comum. Entender como o ELEFE tem sido revisto, ampliado e problematizado pode nos ajudar a compreender o escopo dos cursos do IFA.

Entendemos, baseadas nas ponderações de Celani (1997) e Souza (1977) — dois autores cuja obra tem valor histórico inestimável ${ }^{7}$ — há três grandes marcos sócio-históricos e teórico-metodológicos que nos ajudam a compreender o contexto da elaboração dessas modalidades de ensino-aprendizagem de línguas e o momento em que chegaram ao contexto brasileiro. $\mathrm{O}$ primeiro deles foi o deslocamento do eixo econômico para os EUA, durante as décadas de 1950 e 1960, como consequência do suporte econômico dado aos países europeus que sofreram com a destruição do seu parque industrial e a perda de uma parte significativa de trabalhadores durante a Segunda Guerra Mundial. O segundo foi o desenvolvimento de pesquisa na área de Linguística Aplicada e aquisição de línguas. O terceiro foi a criação dos parâmetros do chamado Threshold Level', em 1971, que serviu de suporte para a elaboração do Quadro Comum Europeu de Referência para Línguas (QCER), na década de 1990. Ao lado desses marcos, os estudos de Noam Chomsky, de 1957, e de Del Hymes, de 1972, nos EUA, sobre uma nova concepção de competência e de competência comunicativa, respectivamente, favoreceram o desenvolvimento da AC para o ensino de LE. E, por fim, os debates sobre uma perspectiva sociointeracionista de língua e aprendizagem que ampliaram as discussões sobre os objetivos, metodologias e modalidades de ensino de LE (CELANI, 1997; PICANÇO, 2003, TILIO, 2013).

O primeiro marco, ambientado no contexto sócio-histórico, é o panorama social e econômico em que se encontram os países europeus frente à então chamada URSS e os EUA. Para visualizarmos esse panorama, precisamos retomar alguns pontos históricos que contribuíram para o seu aparecimento.

Para Hobsbawn (1995, p. 44), a Segunda Guerra Mundial criou entre os países dela participantes — reféns ou apoiadores — um vínculo armamentista e econômico. Esse acordo posicionou as novas potências (URSS e EUA) em lados opostos (HOBSBAWN, 1995, p. 51-5). A Europa percebeu muito cedo a devastação decorrente da guerra e já em 1949, apenas um ano após o reconhecimento público do fim do conflito, criou o Conselho da Europa, uma entidade de personalidade jurídica de direito internacional, que tinha

\footnotetext{
${ }^{7}$ Maria Antonieta Alba Celani e Antônio Cândido de Melo e Souza são daqueles intelectuais brasileiros imprescindíveis para compreender o ensino de línguas no Brasil na formação universitária e sua relação com o contexto histórico das universidades brasileiras dos anos 1970 . As obras citadas aqui têm exatamente esse papel.
} 
como objetivo propiciar um espaço democrático e jurídico comum, organizada em torno da Convenção Europeia dos Direitos do Homem e outros documentos de proteção ao indivíduo, que favoreceriam a proposta de uma Europa unificada décadas mais tarde.

Além desse ambiente sócio-histórico que o mundo experimentava no período das décadas de 1950 e 1960, no âmbito teórico-metodológico do ensino de LE, em decorrência da aplicação de abordagens formalistas — tradicionais ou estruturalistas - os professores experimentavam a frustração no uso de metodologias de ensino que não permitiam adequações à realidade dos alunos (LEFFA, 1988; CELANI, 1997). Essas abordagens praticamente anulavam tais aspectos, privilegiando situações que não representavam sua realidade vivida e suas expectativas de aprendizagem (PICANÇO, 2003), como nos diálogos situacionais em que os alunos deveriam simular viver numa casa com muitos cômodos (que nem sempre era a sua realidade) para praticar modelos frasais e vocabulário. Para isso, o aluno era instado a afirmar gostar de frutas e em seguida negar essa preferência, apenas para internalizar tais modelos. A frustração dos professores repercutia nas pesquisas na área de Linguística Aplicada que ainda era refém das perspectivas formalistas de análise linguística, pautadas por uma concepção sistêmica de língua e behaviorista de aprendizagem. Essa perspectiva, no entanto, já recebia críticas no interior da própria Linguística, em especial da Gramática Gerativista de Noam Chomsky, que tinha como um dos conceitos fundamentais a compreensão da capacidade linguística de um falante nativo ideal como competência, diferente dos seus usos, entendido como desempenho (PONZIO, 2012, p. 77-88). No entanto, foi no âmbito da Linguística Aplicada que novos estudos sobre aquisição de língua e o papel do contexto social colocaram o aprendiz no centro das preocupações.

O etnólogo Del Hymes, a partir de pesquisas sobre a aquisição da língua materna, publicadas em 1972, foi quem trouxe o conceito de competência comunicativa como deslocamento da proposição chomskiana para competência linguística (ALMEIDA, 2010). Embora a competência linguística se configurasse como um conhecimento estático (produto da fixação de parâmetros universais), Hymes cunhou o termo competência comunicativa como processual e dinâmico. Essas discussões foram validadas na Europa no mesmo período em que o Conselho Europeu (CE), visando a unificação política e econômica, buscava formatar uma política linguística baseada num modelo de ensinoaprendizagem aplicável a qualquer língua, e que favorecesse a construção da União 
Europeia (GAJEWSKA; SOWA, 2008; SLAGTER, 2007; CAMARGO, 2008) e o fortalecimento de uma identidade multicultural comum aos europeus ${ }^{8}$.

Essa abordagem, difundida sob o nome genérico de Abordagem Comunicativa (AC), considerada um programa eficiente de ensino, abrigou várias tendências e aportes teóricos, alguns cognitivistas outros sociointeracionistas (AMORAS, 2012; PUREN, 2004), além de enfoques didáticos diversos. O comunicativismo - perspectiva que defende as premissas dessa abordagem - tem sido amplamente criticado por sua insistência nas simulações, baseadas nos usos de um falante nativo ideal (FIGUEREDO, 2011; WALESKO, 2019). A concepção de cultura permanece atrelada a noções e costumes desses falantes ideais que são representados em diálogos situacionais, gerados a partir da aplicação de um programa de funções linguísticas e comunicativas, que promovem no aluno uma percepção inadequada de sua performance linguística como imperfeita (WALESKO, 2019; TILIO, 2013; KRAMSCH, 2017).

Para que esse modelo pudesse ser amplamente utilizado, além do desenvolvimento teórico e acadêmico de novas abordagens linguísticas e metodológicas, desenhou-se um modelo de desempenho comum, em 1971, e, mais tarde, na década de 1990, o Quadro Comum Europeu de Referências (QCER). Esse modelo, e toda sua fundamentação teórica, descrita por linguistas convidados pelo CE, tornou-se um importante instrumento político de compatibilização de novos parâmetros na prática do ensino de LE. Em 1971, quando do Simpósio de Rüschlikon, financiado pelo conselho, definiram-se as bases para o Projeto $\mathrm{n}^{\circ} 4$, que originou o QCER como um quadro de níveis de proficiência idealizado, imposto a todos os cidadãos europeus (e não europeus). O QCER foi (e ainda é) usado para planejar, qualificar, regular e controlar os usos linguísticos na formação de quadros de trabalhadores que tinham (têm) autorização para transitar dentro do continente europeu. Funcionou como medida de incentivo, mas também de controle da migração, em especial de trabalhadores dos chamados países do Terceiro Mundo ${ }^{9}$. Essa e outras medidas foram adotadas partindo-se dos interesses dos países europeus relativos

\footnotetext{
${ }^{8}$ Segundo Camargo (2008, p. 481) alguns autores apostam que, ainda que existam duas dimensões (política e cívica) no projeto de união, elas "podem, no curso do próprio processo de integração, gerar coletivamente uma identidade cívico-cultural pós-nacional em que democracia, direitos humanos, economia de mercado, estado de bem-estar social e diversidade cultural passem a representar os fundamentos de uma nova legitimidade [...] (HABERMAS, 1992; 1994; 1996; LENOBLE, 1992)".

${ }^{9} \mathrm{Na}$ década de 1970, em meio à Guerra Fria, popularizou-se uma interpretação reducionista da Teoria dos Mundos. Assim, os mundos ficaram divididos por referência àquele período histórico: Primeiro Mundo: EUA e países capitalistas aliados; Segundo Mundo: URSS e seus aliados; Terceiro Mundo: países capitalistas subdesenvolvidos ou geopoliticamente não alinhados.
} 
à economia e às relações de trabalho, pois era necessário atrair estrangeiros que se dispusessem a desempenhar funções menos valorizadas pelos europeus (DINIZ, 2012). A onda de imigrantes que surgiu na Europa na década de 1970, incentivada pelas políticas econômicas de reconstrução ${ }^{10}$, gerou um contingente de adultos monolíngues ${ }^{11}$, iniciantes no aprendizado de línguas, que tinham a necessidade da aquisição de LE vinculada às necessidades profissionais. Segundo Gajewska e Sowa (2008 p. 102), esse processo foi o que motivou o surgimento de políticas para o Ensino de Línguas financiadas pelo CE.

Em 1973, Trim organiza e publica os seguintes questionamentos sociais que orientam o desenvolvimento dessa política:

(a) Como promover a integração europeia e a mobilidade das populações desenvolvendo a aprendizagem de línguas?

(b) Como incitar os adultos a aprenderem as línguas e como adaptar da melhor forma esta aprendizagem às necessidades sociais e profissionais tão diversas?

(c) Como decompor o conceito global de línguas em unidades[...] sobre a base de uma análise de grupos particulares de estudantes adultos, segundo as situações nas quais eles são tipicamente enquadrados em temas de comunicação da língua. (TRIM, 1973, p. 9, tradução nossa). ${ }^{12}$

Esses questionamentos, que partem de uma concepção sistêmica de língua - e homogeneizante no que se refere às relações entre sujeito, sociedade e aprendizagem serviram como balizadores para a proposição do Threshold Level' (1971) ${ }^{13}$ e do QCER. Parte-se do pressuposto de que as línguas diferem entre si apenas por constituírem sistemas e normas distintos, e que as formas de dizer, aqui identificadas como funções

\footnotetext{
${ }^{10}$ A imigração visava atrair mão de obra para a reconstrução dos países devastados com a Segunda Guerra Mundial.

${ }^{11}$ Adultos que não se comunicavam em outros idiomas se não exclusivamente por suas línguas maternas. Em geral, essa interpretação se baseava no uso das línguas de prestígio e não levava em conta a diversidade de língua faladas pelas populações dos países latino-americanos, africanos e asiáticos.

12 « (a) Comment promouvoir l'intégration européenne et la mobilité des populations en développant l'apprentissage des langues ? (b) Comment inciter les adultes à apprendre les langues et comment adapter au mieux cet apprentissage à des besoins sociaux et professionnels très divers ? (c) Comment décomposer le concept global de langues en unités [...] sur la base d'une analyse de groupes particuliers d'étudiants adultes, selon les situations dans lesquelles ils sont typiquement placés en matière de communication langagière ». Essa publicação da década de 1970 é um marco na formalização das políticas de ensino de línguas sob as orientações do CE.

${ }^{13}$ A primeira versão do programa foi apresentada em inglês, mas em seguida surgiram suas versões em outras línguas. Em francês é Un niveau Seuil (COSTE et al., 1971).
} 
linguísticas, são correspondentes em todas as línguas europeias e que só resta elencar os modelos frasais e elementos nocionais que compõem cada uma delas, sendo possível atingir um nível limiar de desempenho linguístico em qualquer contexto de ensinoaprendizagem. Segundo Hutchinson e Waters (1994, p. 7, tradução nossa), o pensamento corrente na época era que "se a linguagem varia de uma situação a outra, deveria ser possível da mesma forma determinar as estruturas/formas de situações específicas e então fazer dessas estruturas e formas as bases do curso (de LEM)"14. Nesse sentido, observamos que esses pressupostos não rompem com a premissa estruturalista de que aprendemos língua ao ouvir, falar, ler e escrever - que seguem sendo compreendidas como as quatro habilidades de desempenho linguístico.

Assim como a AC, o ELEFE será organizado em torno de concepções semelhantes e muitos programas usarão o QCER para padronizar o ensino. Dessa forma, entendemos que o desenvolvimento do ELEFE, assim como a AC decorrem de um contexto acadêmico e político comum. Para o ELEFE, alguns avanços significativos sobrevieram nos anos seguintes à década de 1970, quando se iniciaram as ofertas de língua instrumental nas universidades brasileiras para leitura de textos acadêmicos. A AC chegou um pouco mais tarde, respaldada pelas pesquisas em LA que se consolidaram nas décadas de 1980 e 1990 (PICANÇO, 2003).

Durante as décadas seguintes, nota-se uma preocupação ainda maior com a individualização do aluno e suas necessidades (CELANI, 1997), decorrente da preocupação da $\mathrm{AC}$ de manter, em relação ao aprendiz, um foco no sentido - no significado e na interação propositada entre os aprendizes. Surge assim uma das primeiras modalidades de ELEFE, a saber, o ensino de língua funcional/instrumental. Conforme Faleiros (2005, p. 1),

[...] o surgimento do Francês Instrumental (FI), entendido como modalidade de ensino de francês com objetivos específicos, na década de 70, é fruto de uma crise no ensino de Francês Língua Estrangeira (FLE) que, na segunda metade do século XX, perde progressivamente seu papel de língua veicular para o inglês no cenário internacional.

Assim, o conjunto de leituras de Celani (1997) e Faleiros (2005) nos permite concluir que existem duas nomenclaturas para as modalidades no ELEFE - doravante objetivos específicos (ELEOE), nomenclatura mais comum no ensino de francês - a partir da finalidade (relativa a contextos específicos ou a habilidades específicas):

14 "IF language varies from one situation to another, it should be possible to determine the features of specific situations and then make these features the basis of the learner's course". 


\begin{tabular}{|c|c|}
\hline \multicolumn{2}{|c|}{ Ensino de Língua Estrangeira com Objetivos Específicos (ELEOE) } \\
\hline Voltada para contextos específicos & Voltada para habilidades específicas \\
\hline Ex: LE para universitários que farão intercâmbio. & $\begin{array}{c}\text { Ex: LE para universitários, priorizando uma das } \\
\text { habilidades de prática linguística. }\end{array}$ \\
\hline
\end{tabular}

Fonte: as autoras (2020)

A necessidade do desenvolvimento de cursos de ELEOE se intensifica com o fato de que, após a Segunda Guerra Mundial, países como a França, apesar de vitoriosos, estavam devastados, em detrimento da hegemonia econômica até então existente. Daí ocorre uma nova definição política e econômica, gerando a polarização entre EUA e União Soviética como duas novas potências. Conforme destaca Huntington (2010, p. 143), o mundo ocidental, nos anos pós-Segunda Guerra Mundial, torna-se refém dessas forças políticas no talento, pesquisa, e potencial de desenvolvimento científico e inovação tecnológica; e, sendo os Estados Unidos uma potência econômica e o maior representante do mundo Ocidental em inovações científicas e tecnológicas, a língua inglesa passou a exercer uma força centrípeta, com tendências ao monolinguismo, tornando-se, na nomenclatura gravitacional de Calvet (2012, p. 57), uma língua hipercentral ${ }^{15}$.

No Brasil, até a década de 1960, a Língua Francesa (LF) esteve fortemente relacionada à ideia de patrimônio de alta cultura. Conforme o professor Antônio Cândido (SOUZA, 1977), o desenvolvimento do curso de Francês Instrumental tem um aspecto peculiar se comparado às outras línguas estrangeiras. Conforme o autor, a partir da independência dos países da América Latina a cultura francesa desempenhou um papel muito importante. O primeiro deles foi ter nos servido como cultura mediadora (SOUZA, 1977), já que, desde o século XIX, intelectuais brasileiros conseguiam ler obras dos grandes nomes da literatura e da filosofia, entre outras, por meio de traduções francesas.

O segundo papel de importância desempenhado foi o de "substituição [...] das culturas e línguas clássicas pela cultura e língua francesa no que se refere à formação intelectual da América Latina" (SOUZA, 1977, p. 11). Essa substituição era, segundo o autor, uma necessidade, já que nosso (latino-americano) desenvolvimento coincide com dois fatos importantes: o surgimento dos processos de industrialização e a transformação das visões de mundo. Segundo o autor, a LF nos serviu como "um bom instrumento

${ }^{15}$ Da mesma forma, as demais línguas europeias como o português, o francês, o espanhol, o alemão e o italiano também geram, devido à sua importância política e econômica, uma força centralizadora sendo consideradas línguas supercentrais, pois mantêm em sua gravitação outras línguas centrais e periféricas (2012, p. 57). 
do desenvolvimento científico, já que é intimamente elaborada pelo espírito crítico e de pesquisa" dos teóricos franceses. A presença da LF nas universidades representa "essa necessidade, histórica, de mudança do paradigma da imagem da língua francesa não apenas como patrimônio cultural, mas como vetor das revoluções científicas e tecnológicas". (SOUZA, 1977, p. 14). No Brasil, isso significava acesso a uma vasta bibliografia e nas décadas seguintes a possibilidade de qualificar nosso quadro de professores em cursos de pós-graduação em universidades francesas, que depois iriam criar os cursos de pós-graduação em seus departamentos, como nos casos da USP na década de 1940. A vinda de Roger Bastide, em 1941, e sua permanência por mais de 20 anos no Brasil ministrando cursos nos legou uma geração de intelectuais como o próprio Antônio Cândido, o professor Florestan Fernandes, a professora Gilda de Mello e Souza e Maria Isaura Pereira de Queiroz (BRAGA, 2000).

Entre os fatos que compunham essa expectativa estão o surgimento da Associação Brasileira de Ciência $(A B C)^{16}$ que propôs ao governo, em 1946, a criação de um Conselho Nacional de Pesquisa (CNPQ). Em 1951, foi criada a Coordenação Nacional de Aperfeiçoamento de Pessoal de Nível Superior (CAPES), resultado de uma campanha de qualificação de novos quadros. O retorno ao Brasil dos acadêmicos que fizeram aperfeiçoamento no exterior no final da década de 1950 e início da década de 1960 trouxe uma vasta gama de referências científicas em língua estrangeira, interferindo diretamente nos programas e nas referências utilizadas nos cursos de graduação. A falta de traduções disponíveis das obras de referência dos professores desses cursos em língua portuguesa justificava a necessidade de os estudantes universitários desenvolverem a prática de leitura em LF.

Conforme relata Faleiros (2005), durante a década de 1970 no Brasil, o desenvolvimento do ensino do Francês Instrumental (FI) responde às necessidades específicas de alunos de graduação e pós-graduação, relacionada à leitura de textos acadêmicos para o desenvolvimento de pesquisas. Ainda segundo a autora, o contorno desses cursos é definido por seu caráter emergencial e pragmático. Assim, existe uma noção de utilidade e informatividade que prevalece sobre outros aspectos como de valor cultural ou estético do aprendizado da LE, traçando um panorama de compreensão da língua e da cultura francesas contrastantes com aquele desenhado por Antonio Candido (SOUZA, 1977).

Conforme Ramos (2009, s. p.), muitos mitos foram formulados em torno do ensino de língua instrumental. Isso porque embora tenha havido maior atenção à

\footnotetext{
${ }^{16}$ Em 1916 chamava-se Sociedade Brasileira de Ciências. 
compreensão escrita, não era essa a única competência desenvolvida. Ao mesmo tempo, o uso de gramática era proibido apenas nas primeiras aulas para estimular a reflexão do aluno sobre a língua a partir da sua própria experiência linguística, o que também induzia a se pensar erroneamente que era necessário conhecimento prévio na língua. Esses mitos acabaram estigmatizando o ensino não apenas do inglês, mas de LE como um todo, incluindo o caso do FI.

A primeira universidade de que se tem notícia a implementar uma turma de língua instrumental no Brasil é a Universidade de Fortaleza, no Ceará ${ }^{17}$. Contudo a origem da abordagem instrumental no Brasil tem sido reconhecidamente (RAMOS, 2009; BEATO-CANATO, 2011) vinculada ao Projeto Nacional de Inglês Instrumental, liderado pela então coordenadora do Programa de Linguística Aplicada na Pontifícia Universidade Católica de São Paulo, professora doutora Maria Antonieta Alba Celani, na década de 1970. A partir desse panorama, pretendemos, na próxima seção, discutir a forma como se desenvolve o ensino de LF no contexto do ELEOE e, em seguida, analisamos comparativamente dois exemplos de propostas de ensino de FLE que se desenvolveram nos anos 2010 na UFPR, por meio Projeto de Formação em Línguas para Fins Acadêmicos, e na USP, por meio do Projeto de Ensino de Francês com Objetivos Específicos.

\section{MODALIDADES DE ENSINO DE LÍNGUAS COM OBJETIVOS ESPECÍFI- COS E O CONTEXTO BRASILEIRO}

Até aqui, vimos que há várias denominações diferentes para o Ensino de LE com Objetivos Específicos (ELEOE) conforme o país, o contexto de desenvolvimento, a abordagem e os objetivos a serem atingidos. Por conta disso, a comunidade acadêmica (LEFFA, 1988; CELANI, 1997; ALBUQUERQUE-COSTA, 2011) tem se debruçado sobre a questão da terminologia empregada para essa modalidade de ensino.

No caso do Francês como Língua Estrangeira (FLE), o histórico de cursos destinados a grupos ou demandas particulares impulsionou a criação, na França, de programas com objetivos específicos desde 1927, quando combatentes franceses são convocados a preparar um manual aos combatentes não franceses. Um segundo período de demandas foi o aumento de intercâmbios acadêmicos da década de 1960, e a publicação, em 1971, a pedidos do Ministro de Relações Exteriores, pelas edições Hâtier de um manual de FLE de natureza cientifico e técnico, destinado a formar mão de obra

\footnotetext{
17 "Instrumentalidade no ensino de línguas estrangeiras" - coleção documentos universitários 8 - imprensa universitária/UFC — Fortaleza, Ceará, 1981. 
estrangeira. Nessa época começam a surgir os dicionários audiovisuais sob influência do chamado método "estrutural-global audiovisual" (SGAV) de Paul Rvenc e Petar Guberina (MUSTAFA, 2015).

Ainda na década de 1970, mais especificamente, em 1974, o Ministério de Relações Exteriores da França lança um novo programa visando o ensino de FLE segundo grupos específicos de trabalhadores, mas focando em uma abordagem oposta à do Francês Instrumental concebido na América Latina (LEHMANN, 1993), que atendesse às demandas reais de comunicação. Nesse sentido, novos métodos são apresentados: em 1979 é proposto por Sophie Moirand, a partir do livro Situation d'écrits, um método com base nas situações de comunicação, na análise dos atos de fala, na análise do discurso e considerando as necessidades específicas do grupo de estudantes identificados por área de atuação/trabalho. Esse método foi chamado de francês funcional, marcado pela contribuição de Denis Lehmann e Rémy Porquier que acrescentam ao método de Sophie Moirand a análise de discurso autêntico.

Por fim, o termo Francês com Objetivos Especificos (FOE) tem como referência terminológica o Inglês para Fins Específicos, destacando-se sua conexão com a metodologia da $\mathrm{AC}$ e um público de área profissional ou acadêmica específica, que dispõe de tempo limitado para a aprendizagem do francês. Diante da presença de várias terminologias, o que propomos ${ }^{18}$ é que: fins específicos seja associado à opção na qual a finalidade é a do desenvolvimento de alguma habilidade, ainda dentro do quadro da AC; objetivos especificos envolvem contextos específicos de aprendizado, como para intercâmbio ou um ambiente de trabalho, mas que não se limitam a habilidades específicas (como eram os cursos instrumentais para leitura).

O FOE, portanto, está baseado nas necessidades e nas demandas dos alunos e busca fazer um recorte das situações concretas e da temática para definir os procedimentos metodológicos e os itens linguísticos e culturais, de savoir-faire (saber fazer), de comportamentos e situações que serão confrontados no cotidiano dos alunos e que serão,

${ }^{18}$ Outra classificação possível é a citada por Albuquerque-Costa (2012, p. 435): "Mangiante e Parpette (2004), ao retomar essas nomenclaturas, fazem uma diferença mais precisa entre francês de especialidade (Français de Spécialité) e francês para objetivo específico (Français sur Objectif Spécifique - FOS), afirmando que a primeira se refere a um contexto profissional que pode reunir diferentes profissionais que nele atuam, como, por exemplo, na área do turismo (guias turísticos, agentes de viagem, entre outros). No caso de um programa FOS, a demanda é mais precisa e se refere a uma atividade profissional em particular, como, por exemplo, a preparação de enfermeiras brasileiras que precisam aprender francês para realizar um estágio em um hospital em Paris". Assim, a questão da nomenclatura permanece sem um consenso claro entre os autores e por isso estamos propondo esse modo de compreendê-las nesse artigo, pois mais do que debater a nomenclatura, nossa preocupação é compreender essas propostas teórico-metodologicamente. 
portanto, trabalhados nas aulas (PARPETTE; MANGIANTE, 2004). Ainda nesta última encontra-se a terminologia sugerida por Parpette e Mangiante (2011) de Francês com Objetivos Universitários (FOU) que objetiva trabalhar com os estudantes que estão na iminência de iniciar seus intercâmbios acadêmicos num país estrangeiro, e é, portanto, ainda mais específico porque o objetivo é uma pré-integração linguística e cultural.

Os cursos de FOU, especialidade dentro da modalidade de Francês com Objetivos Específicos, segundo Parpette e Mangiante (2011), são preparados a partir dos requisitos centrais daquela modalidade, com o grande diferencial de propor um programa que integra "a dimensão institucional das situações linguísticas visadas e de comportamentos esperados por parte dos estudantes inseridos na universidade francesa" (PARPETTE; MANGIANTE, 2011 p. 147) ${ }^{19}$. Ressaltamos aqui que nossa compreensão de FOU é mais ampla, pois considera a preparação dos alunos antes mesmo de sua seleção para um programa de intercâmbio e engloba universidades francófonas e não apenas as francesas. Além disso, acreditamos que o pré-contato do estudante com a universidade francófona pode ser uma demanda progressiva, pois quase sempre existe uma forte pressão do tempo, uma vez que os estudantes se encontram na iminência ou provável pré-iminência da experiência acadêmica em FLE.

Por fim, propomos, diante das diversas possibilidades terminológicas, o seguinte quadro síntese:

\begin{tabular}{|c|c|}
\hline \multicolumn{2}{|c|}{ Ensino de Língua Estrangeira com Objetivos Específicos ELEOE } \\
\hline Voltada para contextos específicos & Voltada para habilidades específicas \\
\hline $\begin{array}{c}\text { Ex: LE para universitários que farão } \\
\text { intercâmbio }\end{array}$ & $\begin{array}{c}\text { Ex: LE para universitários, priorizando uma } \\
\text { das habilidades de prática linguística }\end{array}$ \\
\hline $\begin{array}{c}\text { Terminologias: } \\
\text { LE com/para Objetivos Específicos }\end{array}$ & $\begin{array}{c}\text { Terminologias: } \\
\text { LE Instrumental/LE para Fins Específicos }\end{array}$ \\
\hline
\end{tabular}

Fonte: as autoras (2020).

Essas modalidades de FOU se tornaram cada vez mais demandadas, especialmente após a intensificação do incentivo à internacionalização das universidades e o fomento aos intercâmbios acadêmicos que se ampliou com a criação do Programa Ciência sem Fronteiras (CsF), que vigorou entre os anos de 2011 e 2017. O Programa tinha o objetivo

\footnotetext{
${ }^{19}$ « la dimension institutionnelle des situations langagières visées, et la dimension cognitive des comportements attendus de la part d'étudiants insères dans l'université 'française'».
} 
[...] de consolidar, expandir e internacionalizar a ciência e tecnologia, a inovação e a competitividade brasileira, por meio do intercâmbio e da mobilidade internacional dos estudantes do ensino superior brasileiro, propicia ao país condições para que estudantes, inclusive de cursos de graduação, possam ser expostos a realidades culturais, científicas e educacionais diferentes. Além disso, cria a oportunidade de tornar estes estudantes proficientes em outra(s) língua(s). (ABREU-E-LIMA, et al. 2017, s. p.).

Desde o início, as IES brasileiras reconheciam a importância do programa, mas apontavam também suas fragilidades, buscando encontrar soluções para o açodamento do seu processo de implementação. Uma avaliação comum à época era de que,

Com a implementação do Programa CsF, entretanto, várias questões emergiram ou tornaram-se ainda mais evidentes, tais como a falta de proficiência em língua estrangeira (ou língua adicional) do alunado brasileiro, a ausência de uma política de internacionalização da educação superior que contemple intercâmbios de alunos de graduação oriundos de outros países, aspectos curriculares e questões relativas a financiamento e infraestrutura das instituições visando a sua internacionalização, formação de professores e língua de instrução, apenas para citar alguns dos temas em debate. (ABREU-E-LIMA, et al. 2017, s. p.).

Além dos problemas com a documentação discente e a validação das atividades desenvolvidas nas universidades de destino, os estudantes enfrentaram os problemas do pouco domínio da língua do país e o pouco conhecimento sobre o cotidiano da vida acadêmica nas universidades em que desenvolveriam seus estágios de intercâmbio. A partir desse diagnóstico, foi criado, em dezembro de 2012, o Programa Inglês sem Fronteiras (IsF), e em 2014, uma nova portaria instituiu o Idiomas Sem Fronteiras (ABREU-E-LIMA; MORAES FILHO, 2017, s. p.)

Antes mesmo da criação do IsF Francês, portanto, a constatação da falta de preparo dos graduandos incentivou as instituições de Ensino Superior a buscarem alternativas para as atividades de internacionalização. Foi nesse contexto que, em 2010, as universidades também ofereceram programas de ensino de FLE, nos moldes do FOU, como a USP — Francês para fins de internacionalização/Ensino de Francês com Objetivos Específicos (FOU) - e a UFPR - Curso de Francês para fins acadêmicos, dentro do Projeto Formação em Línguas para Fins Acadêmicos (IFA). Analisaremos em seguida esses dois exemplos que, identificando nessa demanda um desenho de cursos com recortes discursivos, temáticos e metodológicos de itens linguísticos e culturais 
específicos, buscaram desenvolver as práticas de linguagem para um contexto de imersão na vida acadêmica.

\section{DUAS EXPERIÊNCIAS DE ENSINO DE FRANCÊS COM OBJETIVOS ES- PECÍFICOS}

Para a nossa discussão nesse artigo, realizamos a análise dos programas de ensino de francês com objetivos específicos oferecidos por dois diferentes projetos de extensão, durante os anos de 2011 e 2012, no contexto das primeiras etapas do Programa Ciência sem Fronteiras por duas universidades (USP e UFPR), antes da criação do programa Idiomas sem Fronteiras, que também já contavam com cursos de línguas entre as atividades de extensão oferecidas aos estudantes.

A escolha do programa dos cursos da UFPR para análise se deve ao fato de as autoras desenvolverem atividades no IFA, responsável pelos cursos. A escolha do programa dos cursos da USP ocorreu em virtude do contato que a pesquisa inicial sobre o tema possibilitou a partir do acesso à literatura produzida por sua idealizadora, Heloisa Albuquerque $\operatorname{Costa}^{20}$.

\section{UFPR: Francês para Fins Acadêmicos (IFA) ${ }^{21}$}

O Curso de Francês para fins acadêmicos surgiu junto ao Projeto de Formação em Línguas para Fins Acadêmicos (IFA), no ano de 2009, na Universidade Federal do Paraná. Foi o resultado da percepção de uma demanda existente na universidade de alunos de graduação com interesse de participar dos programas de mobilidade acadêmica e de pós-graduação, e que, devido à situação de fragilidade econômica não tinham acesso aos cursos de língua ofertados pelos centros de línguas. Além disso, os coordenadores do projeto entendiam que os cursos existentes não eram direcionados para as demandas e objetivos do público universitário, tanto da graduação como da pós-graduação: programas de mobilidade, acesso à bibliografia ou pesquisa acadêmica.

Dessa forma, o IFA objetivava responder a uma demanda específica dos estudantes, construindo um programa de quatro módulos de 45 ou 50 horas/aula que

\footnotetext{
${ }^{20}$ A partir do contato inicial com algumas publicações e a página do curso, realizamos uma conversa com a professora Heloisa Albuquerque Costa, via Skype, para uma compreensão mais acurada da proposta.

${ }^{21}$ Nossa intenção, como já dissemos anteriormente, é compreender de que forma os cursos de LF do IFA se aproximavam das expectativas do FOU e se os cursos se encaixavam ou não nessa modalidade.
}

Revista X, v. 16, n. 4, p. 1160-1187, 2021. 
contemplassem as situações que os alunos vivenciam no seu cotidiano — ou vivenciariam — nas realidades acadêmicas, tanto no Brasil quanto nos países de intercâmbio.

A outra demanda que o IFA atendia (e atende) é a dos alunos dos cursos de licenciatura em LE que, devido à falta de espaço de prática profissional vinculada à reflexão, análise e crítica acadêmicas, muitas vezes saem da universidade graduados, mas sem terem vivenciado de forma intensa a experiência da sala de aula e muito menos essa experiência aliada ao estudo aprofundado do tema. Portanto o projeto também oferta aos alunos das licenciaturas em LE um espaço prático-reflexivo, vinculado às disciplinas de metodologia e prática de docência. Os alunos do curso de Letras, à época, participavam do projeto como professores recebendo uma bolsa-instrutor ${ }^{22}$ financiada pela Pró-Reitoria de Assuntos Estudantis (PRAE), parceira do projeto. Além das bolsas eram fornecidas cópias dos materiais para todos os alunos.

Conforme descrito na proposta do curso, pretendia-se que, nos quatro módulos ofertados, os alunos fossem capazes de:

1. interagir em língua estrangeira em breves conversações e apresentações sobre quem é, o que faz e o que pretendo fazer em seu futuro acadêmico;

2. descrever onde vive e explorar alguns aspectos espaciais e identitários (históricos, culturais) do local onde vive e de sua origem.

3. fornecer informações sobre a França e os demais países e regiões francófonas do planeta;

4. discutir as políticas linguísticas do programa de francofonia e suas implicações culturais.

Nos anos de 2011 e 2012 os módulos 1 e 2 ofertados compreendiam os seguintes temas e situações ${ }^{23}$ :

1. O que somos e o que fazemos (auto-apresentação; apresentar alguém; situações de formalidade e informalidade);

2. Como me identifico e como me organizo I (candidaturas; calendários universitários; notícias do universo estudantil);

\footnotetext{
${ }^{22}$ Embora os bolsistas atuassem e tivessem status de professor em formação, esse termo era usado pela Pró-Reitoria de Assuntos Estudantis para todos os bolsistas dos programas de qualificação profissional: línguas, informática e atividades desportivas.

${ }^{23} \mathrm{O}$ programa foi consultado no acervo de documentos do projeto que, nessa época, ainda não estava registrado como projeto de extensão.
} 
3. Como me identifico e como me organizo II (padrões profissionais; como os grupos culturais se vestem; estereótipos culturais);

4. Vida universitária (escolha da carreira; rotina de estudos e práticas culturais e esportivas na universidade);

5. Francofonia (diversidade cultural);

6. Rappel [revisão];

7. Moradia (procurar uma moradia);

8. Localizar-se no espaço (situar-se na universidade);

9. A vida estudantil (rotina universitária).

Observando o programa do curso de Francês do IFA, podemos inferir que, embora traga no título o termo "fins acadêmicos", trata-se de um projeto inserido no escopo do que chamamos aqui de Francês para Objetivos Específicos, na modalidade Francês para Objetivos Universitários (FOU), pois não define uma habilidade específica para ser trabalhada, mas um contexto específico, que seria o contexto acadêmico.

\section{USP: ensino do Francês para Objetivo Universitário (FOU)}

O Projeto de Ensino de Francês para Objetivo Universitário surgiu no campus Politécnico da USP no ano de 2001, e na Faculdade de Letras e Ciências Humanas, no ano de 2010. Segundo Albuquerque-Costa (2012), se enquadra na modalidade FOU por seguir as etapas descritas por Mangiante e Parpette (2004): identificação da demanda, identificação das necessidades de comunicação, coleta, análise e tratamento de dados, preparação das sequências pedagógicas e material didático. A demanda que o curso pretendia atingir era daqueles alunos de graduação ou pós-graduação, candidatos a intercâmbio na França, ou em países francófonos, ou com projeto de realizar seus estudos no exterior. Esse curso tinha, portanto, como objetivo, favorecer a inserção dos estudantes brasileiros no meio universitário francês ${ }^{24}$.

A sua estrutura programática compreendia uma modalidade de 45 horas, sendo três dos encontros presenciais e os demais à distância, por meio da plataforma Moodle.

\footnotetext{
${ }^{24}$ Ver Albuquerque-Costa (2012): "Francês para Objetivo Universitário (FOU) na FFLCH/ USP: formação linguística e discurso universitário para alunos que preparam intercâmbio com a França".
} 
Essa modalidade semipresencial foi escolhida porque apenas a modalidade a distância permitiria reunir alunos de diferentes faculdades da universidade, por meio de módulos comuns e transversais próprios do contexto universitário francês.

Conforme sugerido pelo programa (ALBUQUERQUE-COSTA, 2011), os encontros presenciais compreendiam necessariamente três etapas: I. familiarização com o ambiente virtual de interação e aprendizagem e visita virtual à universidade francesa colaboradora/parceira; II. Avaliações; III. Encerramento.

O programa pretendia atingir seus objetivos por meio da abordagem dos seguintes temas/situações:

1. Familiarização com a plataforma Moodle, elaboração dos perfis dos alunos e visita virtual a uma universidade francesa.

2. Organização dos estudos na França. Escolha dos cursos e grade horária.

3. Apresentação de um projeto de estudos, de pesquisa para professores e colegas.

4. Familiarização com o site canal U. Navegação escolha e justificativa de conferências da área de cada aluno.

5. Compreensão oral de trechos de conferências ou de aulas inaugurais em francês.

6. Anotações de um documento oral, de uma aula, de uma conferência.

7. Expressão escrita: preparação e redação de planos de apresentação de seminários.

8. Apresentação dos seminários.

9. Compreensão oral de diferentes tipos de discurso científicos/ acadêmicos

10. Compreensão da vida na universidade e na cidade: atividades de lazer, de esporte.

11. Compreensão escrita de diferentes tipos de discurso científicos/ acadêmicos (travaux dirigés examen, entre outros).

12. Compreensão escrita de diferentes tipos de discurso científicos/ acadêmicos. 
13. Elaboração de um curriculum vitae uma carta de motivação ou de solicitação ao serviço de relações internacionais.

14. Compreensão escrita e preenchimento de documentos administrativos.

15. Avaliação final.

\section{Diferenças e semelhanças}

Apesar de ambos os cursos se apresentarem para o atendimento a uma demanda similar de estudantes universitários, é possível notar algumas diferenças com relação à demanda, aos requisitos de seleção, e à necessidade ou não de conhecimento prévio do idioma. Esses fatores interferem na formação do público e no desenvolvimento das propostas de ensino.

A demanda no curso de Francês realizado no IFA, pela UFPR, por sua parceria com a PRAE e financiamento da assistência estudantil, atendia um público de graduandos com fragilidade socioeconômica, enquanto o curso ofertado pela USP atendia estudantes universitários, de graduação ou pós-graduação. Partindo dessa característica, acreditamos que as atividades resultem em um direcionamento maior dos estudantes em relação aos tipos de enunciados a serem trabalhados, pois como vimos no Programa do curso de FOU ofertado pela USP, havia uma preocupação maior em que os estudantes pudessem compreender e interagir em situações como conferências e seminários acadêmicos.

Em segundo lugar, consideramos como diferença substancial os requisitos para seleção dos estudantes participantes. O primeiro deles (ofertado pela UFPR) pretendia atender, primeiramente, alunos com fragilidade econômica que buscavam desenvolver atividades acadêmicas em língua estrangeira (francês), seja no Brasil ou no exterior. O segundo, da USP, buscava atender os alunos que estão na iminência de realizar o intercâmbio na França, preparando-os para o ambiente acadêmico a partir do contato prévio com uma universidade francesa.

Nesse sentido, a grande diferença reside no fato de que os materiais e temas preparados e desenvolvidos em sala de aula se destinam a contextos mais ou menos prováveis. No primeiro caso, os alunos poderão conhecer aspectos gerais do ambiente universitário do mundo francófono. Nesse sentido, o tema do intercâmbio em universidade francófonas, que não apenas francesas, será considerado, e por isso é Revista X, v. 16, n. 4, p. 1160-1187, 2021. 
provável que estivessem presentes as variantes do francês e diferenças culturais sobre as práticas e realidades acadêmicas de comunidades distintas. As experiências linguísticas são, portanto, de rotinas acadêmicas comuns ao ambiente urbano e universitário.

No segundo caso, o programa prevê contato prévio com a Universidade acolhedora e o desenvolvimento de atividades de preparo para uma realidade de intercâmbio específica em que será inserido. O programa prevê uma maior aproximação com situações típicas do espaço acadêmico: conferências, seminários, exames, preenchimento de documentos e compreensão de discurso científico/acadêmico.

Desse aspecto também decorre maior ou menor possibilidade de contribuir para ampliação de escolhas de universidades de diferentes nacionalidades. Como vimos anteriormente, ainda que tenha havido uma clara tendência a assumir como referências científicas para o desenvolvimento das universidades brasileiras apenas instituições europeias (e estadunidenses), é preciso questionar esse forte aspecto de colonialidade (MIGNOLO, 2020). Nesse sentido, há necessidade de incentivar a ampliação de possibilidades de intercâmbios. Por isso, esse incentivo não pode ser dado após aprovação em processo seletivo de intercâmbio. Assim, no IFA percebe-se que, além de formação na língua numa perspectiva sociocomunicativa, também se projeta uma formação que rompa com as expectativas mais óbvias e consolidadas de referências culturais e acadêmicas.

A terceira grande diferença entre os cursos é a exigência de conhecimento prévio da língua. O primeiro não exigia, como pré-requisito para seleção, alguma experiência em língua estrangeira. No entanto, o domínio de língua era um requisito no momento da inscrição para os programas de intercâmbio (lembrando que este não era uma exigência no início do projeto). O segundo exigia comprovação de 120 horas de curso de FLE, ou avaliação para comprovação de proficiência, além de aprovação em programa de intercâmbio para participação no curso. Dessa forma, o ponto de partida e, consequentemente, o ponto de chegada previstos pelos programas são diferentes, mesmo que o primeiro curso tenha uma previsão de carga horária total de conclusão do curso em 180 horas e o segundo em 45 horas. A carga horária total de experiência do estudante com o curso de LE é, portanto, aproximada (180 horas em um e 165 horas em outro - se somadas as 120 horas exigidas para ingresso), mas a concentração de atividades relacionadas à experiência acadêmica de intercâmbio poderia ser maior no segundo caso, já que o estudante já sabia em que universidade estudaria.

Apesar de todas essas diferenças demarcarem características específicas para cada um dos cursos, há que se lembrar que ambos compõem uma modalidade de Francês para Objetivos Específicos (CARRAS et al., 2007, p. 15), já que apresentam uma demanda e 
um público específico (estudantes universitários que buscam domínio da língua francesa para experiência acadêmica em FLE no Brasil ou no exterior), lembrando que, dependendo do pré-contato do estudante com a universidade, pode ser uma demanda evolutiva ou não; em ambos casos, também existe uma forte pressão do tempo, já que os estudantes se encontram na iminência ou provável pré-iminência da experiência acadêmica em FLE; e também devemos considerar que em ambos cursos se apresentam fortes considerações sobre o nível de chegada e saída, sobre o tempo que se pode dedicar ao estudo da LE; e, por fim, em ambos, os materiais produzidos para o desenvolvimento da formação em LE são preparados a partir da demanda desse público específico, e contam com as novas tecnologias como lugar ou ferramenta para desenvolvimento dessa formação.

Outro elemento de semelhança entre os cursos é a sua identificação com a corrente teórico-metodológica socionteracionista ou sociocomunicativa, pois ao trabalharem com materiais autênticos e gêneros de interesse dos estudantes, compreendem a "complexidade da materialização da comunicação em práticas sociais por textos" (BEATO-CANATO, 2011, p. 858), incluindo o desenvolvimento de aulas que identificam, a partir de textos, tipos de interações sociais, gêneros de discurso, unidades e estruturas linguísticas a serem trabalhadas (BEATO-CANATO, 2011, p. 859).

Após a análise dos programas podemos sintetizar desse modo os dois cursos a partir das referências definidas anteriormente sobre o FOU:

\begin{tabular}{|c|c|c|}
\hline FOU & IFA/UFPR (2011 -12) & PFOU/USP(2011- 2012) \\
\hline Demandas & alunos de graduação & $\begin{array}{c}\text { alunos de graduação e pós- } \\
\text { graduação aprovados em } \\
\text { programas de intercâmbio }\end{array}$ \\
\hline Necessidades & $\begin{array}{c}\text { aspectos gerais da vida dentro } \\
\text { da experiência universitária }\end{array}$ & $\begin{array}{c}\text { atividades acadêmicas em } \\
\text { uma universidade francesa }\end{array}$ \\
\hline Conhecimento prévio & nenhum & 120 horas de FLE \\
\hline $\begin{array}{c}\text { Práticas de linguagem } \\
\text { produção e compreensão } \\
\text { de gêneros orais e escritos, } \\
\text { verbo-visuais e audio-visuais) }\end{array}$ & todas são contempladas & todas são contempladas \\
\hline
\end{tabular}

Fonte: as autoras (2020). 


\section{CONSIDERAÇÕES FINAIS}

Reconhecer a história do ensino de LE com objetivos específicos é reconhecer o projeto político por trás dos incentivos à internacionalização (PICANÇO, 2019; (ABREU-E-LIMA et al., 2017), que longe de ser samaritano, revela uma forte inclinação à exploração de mão de obra provinda de países subdesenvolvidos, e a perpetuação de uma hegemonia cultural por meio das ciências e das universidades. É papel hoje, das universidades, professores e alunos, não apenas reconhecer que essa é uma ação glotopolítica, mas refletir, problematizar e agir criticamente sobre ela. Assim, embora ambos os projetos contemplem demandas legítimas e importantes, os cursos oferecidos no IFA ampliam essa possibilidade de contemplar outras demandas, não tão institucionalmente consolidadas e privilegiadas por políticas linguísticas subalternizadas.

A partir das características dos cursos analisados no contexto da globalização neste início do século XXI, foi possível perceber que mesmo com todas as diferenças que moldam a identidade de cada um deles, como a diferença no contexto de criação, no reconhecimento de públicos, na proposição de alternativas para atender a demanda localizada, o objetivo principal é, em ambos casos, a inserção do aluno numa experiência acadêmica que envolve o intercâmbio estudantil, o que se dá pela oferta de temas relevantes nos programas de ambos cursos, e, nesse sentido, consideramos que ambos cursos também se enquadram na submodalidade de FOU. As formas de atuação para alcançar esses objetivos também se assemelham quanto à aproximação com a perspectiva teórico-metodológica do sociointeracionismo.

A partir destas breves considerações pretendemos contribuir com as discussões da área de LA, trazendo um estudo comparativo de propostas de ensino de FLE, buscando soluções para os embates entre as várias nomenclaturas, esclarecendo nossa compreensão sobre as possíveis modalidades de ensino, identificando cada uma das propostas como FOU e exemplificando as diferentes formas de elaboração de propostas de realização dessa modalidade, que ocorreram concomitantemente, em universidades distintas, e que consideram finalidades específicas de interação. Essas análises também permitem sugerir para futuras pesquisas em que sejam comparativamente analisados: o desenvolvimento do ensino de LE com objetivos específicos em outros países e programas de intercâmbio; a identificação da perspectiva sociocomunicativa ou sociointeracionista em cursos de LE instrumentais; a comparação entre cursos de FLE e cursos de FOU, dentre outras. 


\section{REFERÊNCIAS}

ABREU-E-LIMA, D. M.; SARMENTO, S.; MORAES FILHO, W. B. (org.). Do Inglês sem fronteiras ao Idiomas sem fronteiras: a construção de uma política linguística para a internacionalização. Belo Horizonte: Editora UFMG, 2017.

ABREU-E-LIMA, D. M.; MORAES FILHO, W. B. O Programa Idiomas sem Fronteiras. In: ABREU-E-LIMA, D. M.; SARMENTO, S.; MORAES FILHO, W. B. (org.). Do Inglês Sem fronteiras ao Idiomas Sem Fronteiras: a construção de uma política linguística para a internacionalização. Belo Horizonte: Editora UFMG, 2017.

ALBUQUERQUE-COSTA, Heloisa B. de. Ensino do Francês para Objetivo Universitário (FOU): um dispositivo a distância de formação aux savoir-faire académiques para estudantes universitários que se preparam para estudar em universidades francesas. Revista Intercâmbio, v. 23, p. 47-63, 2011. São Paulo: LAEL/PUCSP.

ALBUQUERQUE-COSTA, Heloisa B. de. Francês para Objetivo Universitário (FOU) na FFLCH/USP: formação linguística e discurso universitário para alunos que preparam intercâmbio com a França. Estudos Linguísticos, São Paulo, v. 41, n. 2, p. 433-442, maio/ ago. 2012. Disponível em: http:/www.gel.hospedagemdesites.ws/estudoslinguisticos/ volumes/41/el.2012_v2_red_hel.pdf. Acesso em: 13 ago.2020.

ALMEIDA, Virgílio Pereira de. Competência Comunicativa e Abordagem Comunicativa: Dell Hymes fragmentado. Signo. Santa Cruz do Sul, v. 35 n. 59, p. 44-57, jul./dez. 2010. Disponível em: http://online.unisc.br/seer/index.php/signo/index. Acesso em: 13 ago. 2020.

ALMEIDA FILHO, José Carlos Paes. A página omissa: contribuições para uma história do ensino de línguas no Brasil. Entre Línguas, Araraquara, v. 1, n. 2, p. 195-202, jul./ dez. 2015.

AMORAS, Aluana Vilhena. Principais metodologias de ensino de Francês Língua Estrangeira. Estação Científica (UNIFAP), Macapá, v. 2, n. 2, p. 41-53, jul./dez. 2012.

BAKHTIN, Mikhail. Estética da criação verbal. São Paulo: Martins Fontes, 1997.

BEATO-CANATO, A. P. M. O trabalho com línguas para fins específicos em uma perspectiva interacionista sociodiscursiva. RBLA, Belo Horizonte, v. 11, n. 4, p. 853$870,2011$.

BRAGA, Maria Lucia de Santana. A recepção do pensamento de Roger Bastide no Brasil. Sociedade e Estado. Brasília, v. 15, n. 2, jun./dez. 2000. 
BRASIL. Secretaria de Educação Fundamental. Parâmetros curriculares nacionais: terceiro e quarto ciclos do ensino fundamental: introdução aos parâmetros curriculares nacionais. Brasília: MEC/SEF, 1998.

BRASIL. Lei 1310 de 15 de janeiro de 1951. Diário Oficial da União, seção 1, 16 jan. 1951, p. 809.

CARRAS, Catherine; KOHLER, Patricia; TOLAS, Jacqueline; SZILAGYI, Elisabeth. Le français sur Objectifs Spécifiques et la classe de langue. Paris: CLE International, 2007.

CALVET, Louis Jean. Nouvelles perspectives sur les politiques linguistiques: le poids des langues. Gragoatá, Niterói, 2012, n. 32, p. 55-73.

CELANI, Maria Antonieta Alba (org.). Ensino de segunda língua - redescobrindo as origens. São Paulo: Educ, 1997.

CHAVES, Daniele Fonseca. O Ensino de Línguas para Fins Específicos como uma proposta de abordagem da Língua Estrangeira no Ensino Médio. 2006. Dissertação (Mestrado em Linguística Aplicada). UnB, 2006.

COSTA, Daniel. Un Niveau Seuil. Hatier: Paris, 1971.

DINIZ, Deize Fernandes. Crenças sobre o processo de aprendizagem de línguas em uma abordagem instrumental. 2012. Dissertação (Mestrado em Letras). Santa Maria/ UFSM, 2012.

FALEIROS, Rita Jover. Francês instrumental: por uma precisão terminológica. In: FBPF. CONGRÈS BRÉSILIEN DE PROFESSEURES DE FRANÇAIS, 15. 2005.

FERREIRA, Luciane Maria Coutinho Buchholz; ROSA, Maria Angélica Souza Da. A origem do Inglês instrumental. Helb. v. 2, n. 2, 2008.

FIGUEREDO, Carla Janaina. O falante nativo de inglês versus o falante não-nativo: representações e percepções em uma sala de aula de inglês. Linguagem \& Ensino, Pelotas, v. 14, n. 1, p. 67-92, jan./jun. 2011.

FIORIN, José Luiz (org.). Introdução à linguística. São Paulo: Contexto, 2002.

GAJEWSKA, Elzbieta; SOWA, Magdalena. Cadre Européen Commun de Référence et enseignement sur objectifs professionnels. Synergies Espagne, n. 1, p. 101-111, 2008. 
GUBERINA, Petar. Comment est conçue la structure dans la method audiovisuelle structure-globale (SGAV, en serbo-croate AVGS). Linguistica. v. 24, n. 1, p. 217-227, 2015.

HOBSBAWN, Eric. A era dos extremos. São Paulo: Schwarcz, 1995.

HUNTIGTON, Samuel P. O choque de civilizações e a Recomposição da Ordem Mundial. Rio de Janeiro: Objetiva, 2010.

HUTCHINSON, T.; WATERS, A. English for specific purposes. Glasgow: Cambridge University Press, 1994.

KRAMSH, Claire. Cultura no ensino de língua estrangeira. Bakhtiniana, São Paulo, v. 12, n. 3, p. 134-152, set./dez. 2017.

LEFFA, V. Metodologia do ensino de línguas. In: BOHN, H. I.; VANDRESEN, P. Tópicos em linguística aplicada: o ensino de línguas estrangeiras. Florianópolis: Editora da UFSC, 1988, p. 211-236.

LEFFA, V. O ensino das línguas estrangeiras no contexto nacional. Revista Contexturas, São Paulo, n. 4, p. 13-24, 1999.

LEHMANN, Denis. Objectifs spécifiques en langue étrangères. Les programmes en question. Paris: Hachette, 1993.

LLOBERA CÀNAVES, Miquel. (coord.). Competencia comunicativa - documentos básicos em la enseñanza de lenguas extranjeras. Madrid: Edelsa, 1995.

MIGNOLO, Walter D. Histórias locais/rojetos globais: colonialidade, saberes subalternos e pensamento liminar. Belo Horizonte: Editora da UFMG, 2020.

MUSTAFA, Bouglimina. Les difficultés et les besoins langagiers en compréhension de l'écrit chez les étudiants de médecine. Dissertação. Université Mohamed KhiderBiskra. 2015.

PARPETTE, Chantal; MANGIANTE, Jean-Marc. Le Français sur Objectif Spécifique: de l'analyse des besoins à l'élaboration d'un cours. Paris: Hachette, 2004.

PARPETTE, Chantal; MANGIANTE, Jean-Marc. Le Français sur Objectifs Universitaires. Grenoble: PUG, 2011. 
PICANÇO, Deise Cristina de Lima. História, memória e Ensino de Espanhol (19421990): as interfaces do ensino de língua espanhola como disciplina escolar a partir da memória dos professores, métodos de ensino e livros didáticos no contexto das reformas educacionais. Curitiba: Editora UFPR, 2003.

PICANÇO, Deise Cristina de Lima. Aspectos políticos, discursivos e subjetivos da interculturalidade na formação do professor de espanhol como LE. Eutomia, Recife, v. 1, p. 303-324, 2012.

PICANÇO, Deise Cristina de Lima. Ética e Formação linguística para a vida acadêmica: o projeto IFA e a internacionaliação na UFPR. Linguagens - Revista de Letras, Artes e Comunicação, Blumenau, v. 13, n. 1, p. 9-29, jan./abr. 2019.

PONZIO, Augusto. Linguística Chomskyniana e ideologia social. Curitiba: Editora da UFPR, 2012.

PUREN, Christian. Marco europeo común de referencia para el aprendizaje y la enseñanza de las lenguas. Estrasburgo: Comité de la educación, Consejo de Europa, edición provisonal 1996 [2ª ed. provisional 1998, ed. definitiva 2001]. 2004.

RAMOS, Rosinda de Castro Guerra. ESP in Brazil: history, new trends and challenges. In: KRZANOWSKI, M. (org.). Current developments in English for Academic and Specific Purposes in Developing, Emerging and Least-Developed Coutries. Reading: Garnet Publishing, 2009. Disponível em: http://www.teachingenglish.org.uk/sites/ teacheng/files/ESPBrazil_Ramos_.pdf. Acesso em: 13 ago. 2020.

ROCHA, Claudia Hilsdorf. Propostas para o inglês no ensino fundamental I público: plurilinguismo, transculturalidade e multiletramentos. 2010. Dissertação (Doutorado em Linguística Aplicada). Universidade Estadual de Campinas. 2010.

SLAGTER, Peter J. Nivel Umbral. MarcoELE Revista de didáctica ELE. n. 5, 2007.

SOUZA, Antônio Cândido de Mello e; CARONI, İtalo; LAUNAY, Michel. O francês instrumento de desenvolvimento. In: SOUZA, Antônio Cândido de Mello e; CARONI, İtalo; LAUNAY, Michel. O Francês Instrumental, a experiência da Universidade de São Paulo. São Paulo: Hemus, 1977. p. 9-17.

TILIO, Rogério. Repensando a abordagem comunicativa: multiletramentos em uma abordagem consciente e conscientizadora. In: ROCHA, C. H.; MACIEL, R. (org.). Língua estrangeira e formação cidadã: por entre discursos e práticas. 1. ed. Campinas: Pontes, 2013, v. 1, p. 51-67. 
TRIM, John. Systèmes d'apprentissage des langues vivantes par les adultes. Strasbourg: Conseil de l'Europe, 1973.

VAN DUNG, Nguyen. Une recherche action en français sur objectifs universitaires dans la region. Synergies Pays riverains du Mékong. n. 2, 2010.

VOLÓCHINOV, V. Marxismo e filosofia da linguagem: problemas fundamentais do método sociológico na ciência da linguagem. São Paulo: Editora 34, 2017.

WALESKO, Ângela Maria Hoffmann. Formação Inicial e o mito do falante nativo: construções identitárias de professores de inglês em uma comunidade de prática. Tese (Doutorado em Letras). Setor de Ciências Humanas da UFPR, 2019.

Recebido em: 14 ago. 2020.

Aceito em: 07 out. 2020. 